\title{
Citrus can help prevent vitamin A deficiency in developing countries
}

\author{
by Betty J. Burri, Jasmine S. T. Chang, and \\ Tami Turner
}

California is a major producer of tangerines and oranges, which contain carotenoids that form vitamin A. Deficiencies of this vitamin are common in southern Asia and Africa, causing blindness and more than one-half million deaths each year. We evaluated the potential of tangerines and oranges to prevent vitamin A deficiency worldwide by measuring their carotenoid concentrations, estimating the amounts needed to meet the recommended safe nutrient intake for vitamin $A$ and determining their availability in countries with vitamin A deficiency. We conclude that tangerines - particularly Satsuma mandarins, which have high concentrations of the carotenoid beta-cryptoxanthin - but not oranges, could be useful in preventing vitamin $A$ deficiency, though not as the sole source.

$\mathrm{V}$ itamin A is essential for normal eyesight, growth and development (IOM 2000). Deficiency in vitamin A rarely occurs in California, but it is a serious health problem for most of the developing world, especially southern Asia and sub-Saharan Africa (WHO 2009) (fig. 1). More than 600,000 people, mostly young children and pregnant women, die each year from vitamin A deficiency (Black et al. 2008). It is also the leading cause of preventable blindness in the world (Sommer et al. 1996).

The amount of dietary vitamin A that a person needs depends on age and sex, whether pregnant or lactating, and presumably on genetics and lifestyle. Recommended amounts of nutrients for healthy individuals are called dietary reference intakes (DRI) in the United States (IOM 2000) and recommended nutrient intakes (RNI) in most of the rest of the world. Although DRI and RNI are based on the same scientific evidence, they vary slightly (table 1).

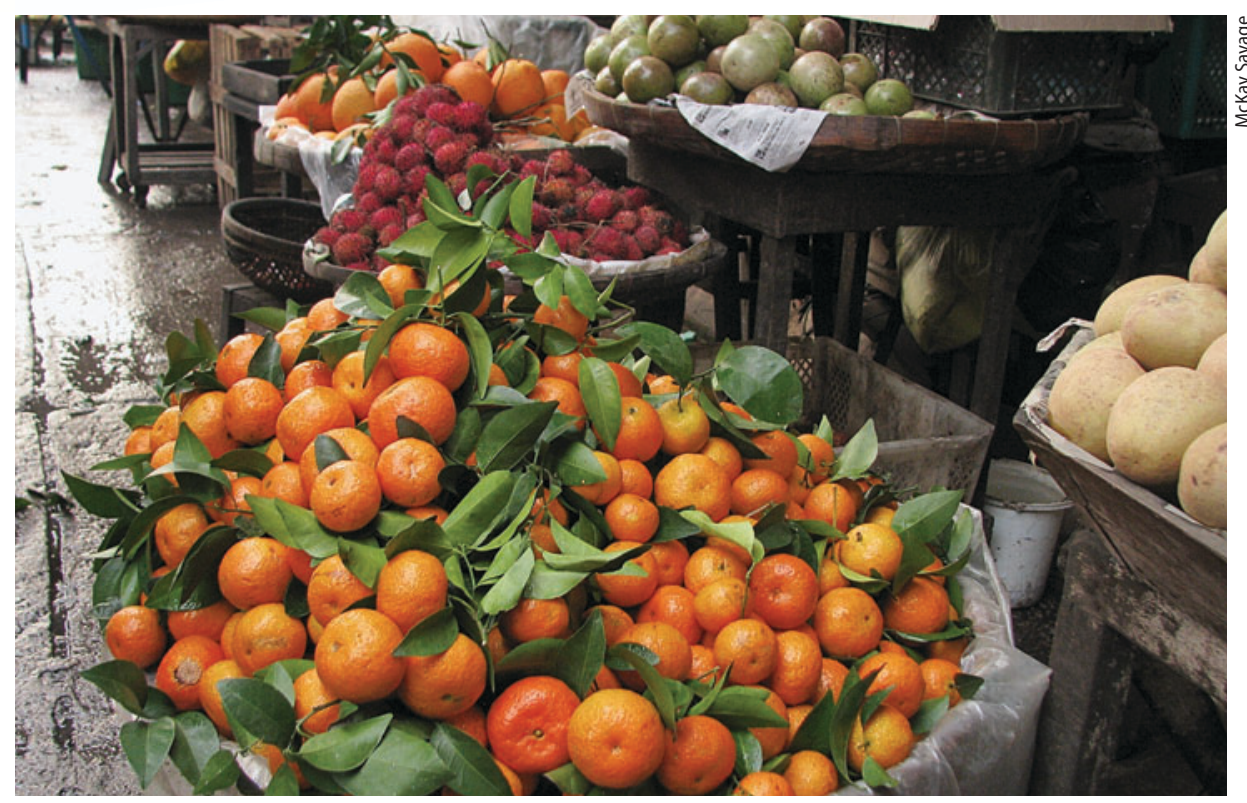

Oranges and tangerines are major sources of beta-cryptoxanthin, which provides easily absorbed vitamin A. Increasing the consumption of tangerines, particularly Satsuma mandarins (above, in Vietnam), could help reduce vitamin A deficiency in developing countries.

Humans can get their RNI of vitamin A from animal-derived foods such as organ meats (the best source is liver). However, organ meats are scarce and too expensive for most of the world's population to eat regularly. Fortunately, vitamin $\mathrm{A}$ is also formed in the body from carotenoids, brightly colored phytonutrients found in fruits and vegetables. The most common vitamin A-forming carotenoids are beta-carotene, alpha-carotene and beta-cryptoxanthin. Of the three, beta-carotene is the most widely distributed in plants. It is found in many green or orange vegetables and fruits, such as carrots, orange sweet potatoes, mangos, spinach and pumpkin. Alphacarotene is mostly in carrots. Beta-cryptoxanthin is found in orange fruits, such as tangerines, oranges, papaya and persimmons, and also in red peppers (USDA ARS 2009).

RNI reports in retinol equivalents (RE); DRI reports in retinol activity equivalents (RAEs). Both are measures of how much vitamin A is formed from carotenoids. In a test tube, one molecule of beta-carotene could be converted into two molecules of vitamin A, and one molecule of alphacarotene or beta-cryptoxanthin into one molecule of vitamin A. In the body, these carotenoids produce far less RAE than in the test tube: current estimates are onetwelfth (FAO 2004) or one twenty-fourth (IOM 2000) of the test-tube RAE. The reason for this difference is because carotenoids are poorly absorbed from most foods (de Pee et al. 1998; Veda et al. 2006).

Absorption depends on many factors, including the type of carotenoid, the food it is contained within, and the diges-
Recent research has suggested that foods rich in beta-cryptoxanthin, such as tangerines and oranges, are surprisingly good sources of vitamin A.

tive health, vitamin status and genetic makeup of the individual. Beta-carotene is better absorbed from orange fruits and vegetables than from leafy green vegetables (de Pee et al. 1998). Recent research has suggested that foods rich in betacryptoxanthin, such as tangerines and oranges, are surprisingly good sources

Online: http://californiaagriculture.ucanr.org/ landingpage.cfm?article=ca.v065n03p130\&fulltext=yes DOI: 10.3733/ca.v065n03p130 
of vitamin A, even though beta-carotene could produce more RAEs based on its chemistry. Burri et al. (2011) found that beta-cryptoxanthin appears to be absorbed significantly better than betacarotene from mixed diets. Recent research in animals by Davis et al. (2008) suggests that foods rich in betacryptoxanthin are equivalent to those rich in beta-carotene as sources of vitamin A.

Encouraged by these findings, we decided to evaluate whether oranges and tangerines, the primary food sources for beta-cryptoxanthin in most of the world, could be used to prevent vitamin A deficiency. We determined the carotenoid concentrations of fresh oranges and fresh and canned tangerines, and calculated the amount of these fruits needed to meet the RNI for one at-risk individual (FAO 2004) as well as the amount of these fruits needed to meet the RNI for all at-risk populations (WHO 2009). We then reviewed the extent and distribution of orange and tangerine production, and identified countries that were major producers of each fruit. We evaluated the effect of increasing production in developing countries with food deficits (those which currently cannot produce enough food to feed their populations) and compared yields to those achieved in California. Production and nutrient data were collected from library and Internet searches.

\section{Vitamin A deficiency programs}

Providing vitamin A supplements or vitamin A-rich foods to people with vitamin A deficiency seems to decrease the severity of diseases such as influenza and diarrhea, and reduce infant and postpartum maternal mortality by about 30\% (Black et al. 2008; FAO 2004). Vitamin A deficiency is usually prevented by food fortification or distributing highdose vitamin A capsules twice a year.

Supplements. Vitamin A supplementation programs are cost-effective nutrient

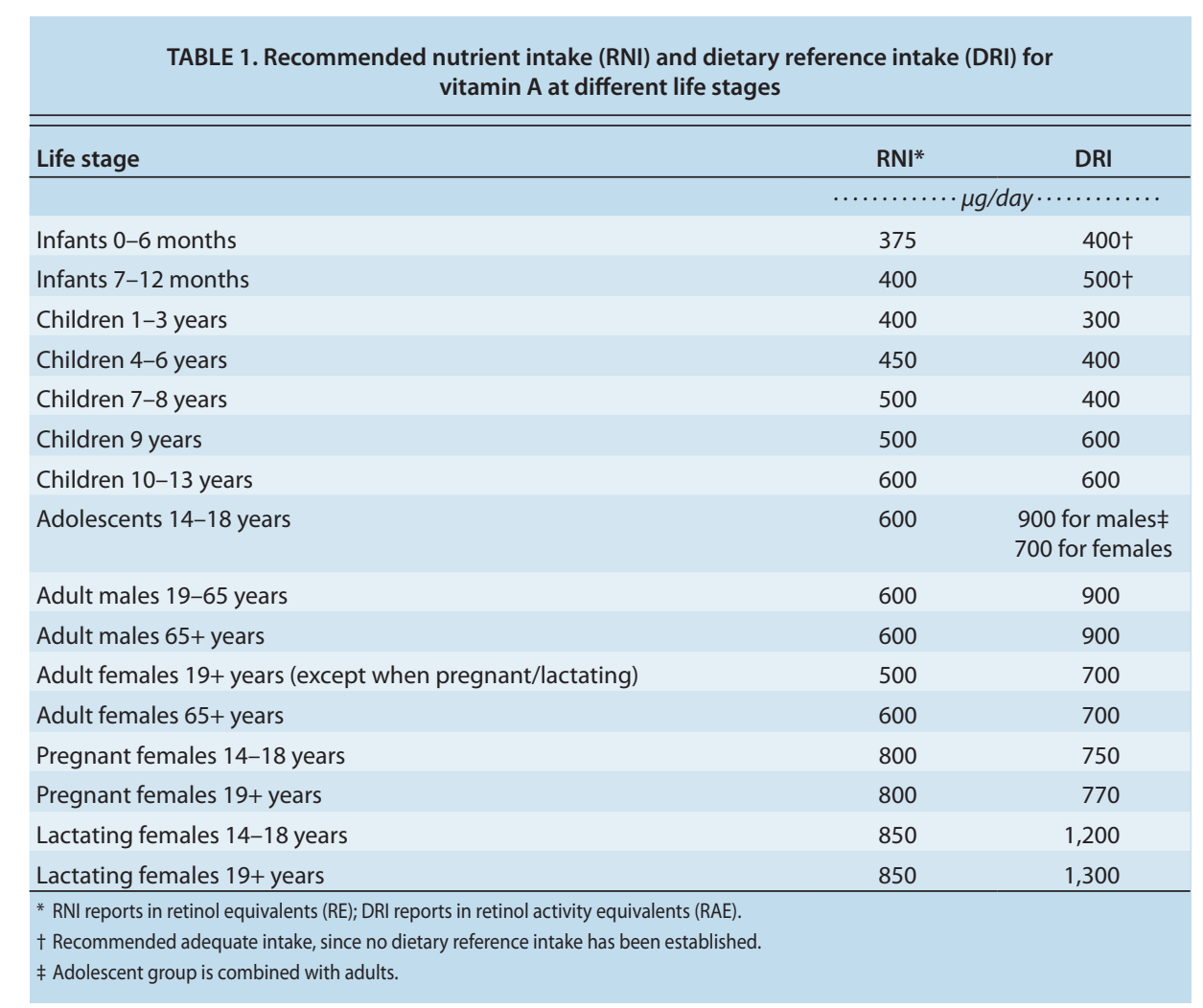

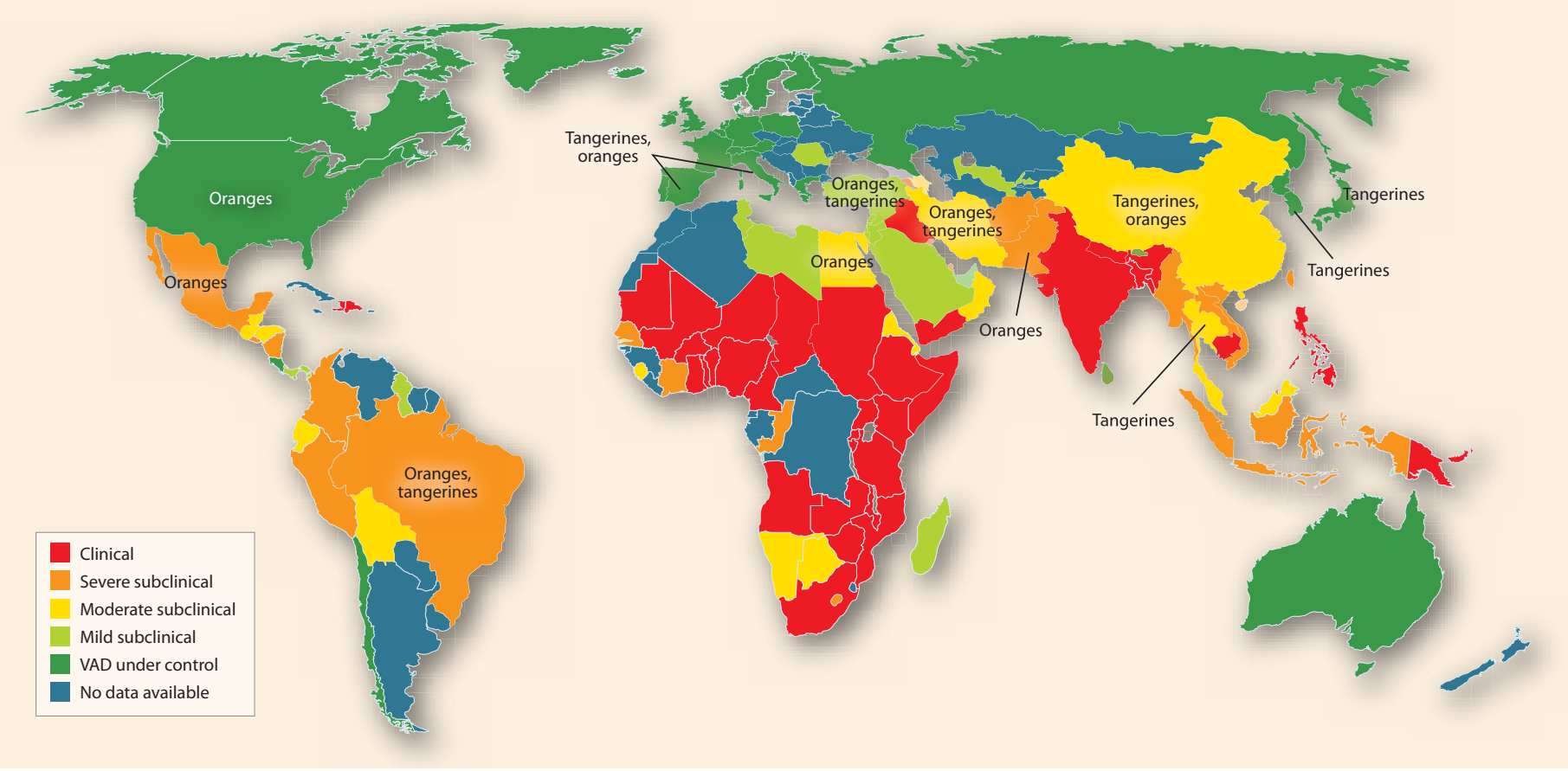

Fig. 1. Vitamin A deficiency (VAD) prevalence (clinical and subclinical) and regions of orange and tangerine production (WHO 2009). 
interventions supported by several national governments and international charitable organizations (including the Bill and Melinda Gates Foundation and California-based Vitamin Angels), but these programs have been difficult to sustain. Coverage - the number of people who are given nutritional supplements compared to the number who should receive them - is often incomplete. For example, India has supported national vitamin A supplementation programs for 40 years but has attained less than $25 \%$ coverage (Stein et al. 2006). Furthermore, vitamin A capsule supplementation programs were suspected of causing death through inadvertent overdosing (Mudur 2001), although research suggests that these suspicions were unfounded (West and Sommer 2002).

Food fortification. Programs that fortify foods such as sugar and oil with vitamin A are another popular and cost-effective way to prevent vitamin A deficiency, and they have been quite effective in Central America. However, it has been difficult to expand these programs, mostly because of problems inherent in food fortification. The food must be consumed by almost everyone, including the poorest people. The amounts eaten must not differ greatly: the food must prevent
Some national governments run vitamin A supplementation programs; they are cost effective, but reaching most people at risk of vitamin A deficiency has proved challenging. Right, vitamin A distribution in Afghanistan.

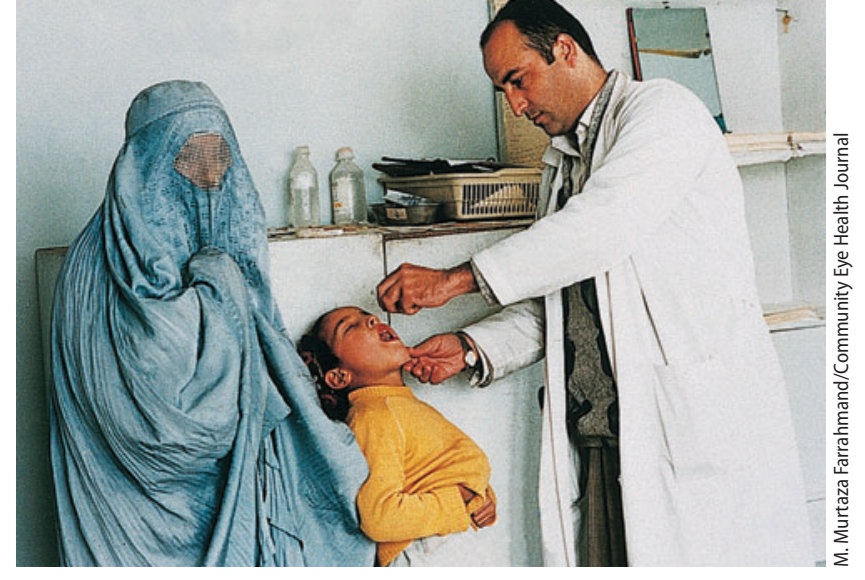

vitamin A deficiency in most people but not cause toxicity in those who eat more than average amounts. Also, food processors and manufacturers generally want fortified foods to look and feel exactly the same as the unfortified foods, which limits the type of nutrient that can be added.

Fruits and vegetables. Growing produce rich in vitamin A-forming carotenoids is an attractive alternative to vitamin A supplements (Ruel 2001). Fruits and vegetables can provide a variety of nutrients in addition to vitamin A - citrus is also a well-known source of vitamin $C$ and fiber - and generate income for small farmers and shopkeepers. Long-term sustainability might be achievable because fruit and vegetable seeds can be harvested and shared at the local level.

TABLE 2. Estimated carotenoids in 100 grams (edible portion) of tangerines and oranges, and two foods (mangos and sweet potatoes) already used to prevent vitamin A deficiency

\begin{tabular}{|c|c|c|c|}
\hline \multirow[b]{2}{*}{ Food (information source) } & \multicolumn{3}{|c|}{ Estimated carotenoid content* } \\
\hline & Beta-carotene & Alpha-carotene & Beta-cryptoxanthin \\
\hline & & - RAE/100 grams.. & . \\
\hline \multicolumn{4}{|l|}{$\begin{array}{l}\text { Tangerine ( } 1 / 2 \text { cup or } 1 \text { medium } \\
\text { tangerine) }\end{array}$} \\
\hline Raw (USDA ARS 2009) & 13 & 4.2 & 34 \\
\hline Raw (USDA ARS 1993) & 13 & 4.2 & 88 \\
\hline Raw (Burri, this report) & $1.1-23$ & $0.6-4.6$ & $41-247$ \\
\hline Raw (Schlatterer and Breithaupt 2005) & Not measured & Not measured & 63 \\
\hline Raw (Yano et al. 2005) & $4.5-16$ & $0-3.8$ & $88-249$ \\
\hline Canned, drained (USDA ARS 2009) & 30 & 5.5 & 64 \\
\hline Canned, drained (Burri, this report) & $9-22$ & $1.7-4.8$ & $83-233$ \\
\hline \multicolumn{4}{|l|}{ Orange ( 1/2 large orange) } \\
\hline Raw (USDA ARS 2009) & 5.5 & 0.5 & 9.6 \\
\hline (Schlatterer and Breithaupt 2005) & Not measured & Not measured & $6.0-15$ \\
\hline (Yano et al. 2005) & 4.3-6 & $0-0.8$ & $23-38$ \\
\hline \multicolumn{4}{|l|}{ Mango ( 3/5 cup) } \\
\hline (USDA ARS 2009) & 37 & 0.7 & 1.0 \\
\hline (Perkins-Veazie 2007) & $41-217$ & Not measured & Not measured \\
\hline \multicolumn{4}{|l|}{ Sweet potato, orange-fleshed } \\
\hline ( 2/5 cup) & & & 0 \\
\hline Canned, drained (USDA ARS 2009) & 458 & 0 & 0 \\
\hline Boiled (USDA ARS 2009) & 787 & 0 & 0 \\
\hline Baked (USDA ARS 2009) & 959 & 3.6 & 0 \\
\hline
\end{tabular}


the winter when other fruits and vegetables are scarce.

\section{Carotenoid concentrations}

Oranges and tangerines have significant concentrations of beta-carotene and beta-cryptoxanthin (table 2).

Concentrations vary with the species and variety of orange and tangerine, and with growing, harvesting and storage conditions (Rodriguez-Amaya 2003). Data compiled by the U.S. Department of Agriculture (USDA ARS 2009) does not specify the variety of tangerines tested. Other data shows that the variety of fruit tested is important (Perkins-Veazie 2007; Yano et al 2005). Satsuma mandarins (Citrus reticulata unshui), for example, have much higher amounts of betacryptoxanthin than clementines (Citrus reticulata blanco), which in turn have more than other citrus fruits such as oranges and grapefruits. This probably explains the high carotenoid concentrations seen in canned tangerines, which are often Satsuma mandarins.

We collected data from several laboratories and measured carotenoid concentrations in fresh and canned tangerines in our laboratory, then compared the results to data for mangos and sweet potatoes, two foods that have been used in successful small-scale interventions to prevent vitamin A deficiency. Carotenoid concentrations were measured by highperformance liquid chromatography, although the methodologies differed.

\section{How much fruit must be eaten}

We calculated the amount of tangerines and oranges needed to supply one person with the RNI of vitamin A (FAO 2004) (tables 1 and 2). For the best-case scenario, we used the highest estimated RAEs listed for oranges ( 6 from betacarotene, 1 from alpha-carotene and 38 from beta-cryptoxanthin) for a total of 45 RAEs in 100 grams of orange. The bestcase scenario of RAEs for tangerines was 30 from beta-carotene, 6 from alphacarotene and 249 from beta-cryptoxanthin, for a total of 285 RAEs in 100 grams. We compared these results to mangos and sweet potatoes. The best case for mangos was 217 RAEs in 100 grams, while the best case for orange-fleshed sweet potatoes was 963 RAEs in 100 grams.

We then estimated the amount of carotenoid-rich food needed to meet the recommended safe nutrient intake of vitamin A (FAO 2004) in people at various life stages, based on the unrealistic assumption that all of the vitamin A in the diet would be derived from that food. The serving sizes used were 1 cup of tangerine slices, sweet potatoes or mango (which weighed 195, 255 and 165 grams, respectively); or 1 large orange (weighing 184 grams) (USDA ARS 2009).

Our calculations showed that the RNI for vitamin A could not be met by eating oranges. Even under the best-case scenario, the amount of orange needed to meet the RNI ranged from 396 grams (two oranges) per day for 1- to 3-year-old children, to 866 grams (4.25 oranges) per day for lactating women. It would also be difficult to achieve the RNI of vitamin A for lactating women solely by eating mangos or tangerines (table 3). They would have

TABLE 3. Estimated grams and servings per day (cups) needed to meet recommended nutrient intakes (RNI) for vitamin A at different life stages

\begin{tabular}{|c|c|c|}
\hline \multirow[t]{2}{*}{ Life stage } & \multicolumn{2}{|c|}{ Food needed to meet RNI } \\
\hline & grams/day & servings/day (cups) \\
\hline Infants $0-12$ months & Assumed mostly breastfed & NA \\
\hline \multicolumn{3}{|l|}{ Children $1-3$ years } \\
\hline Tangerine & $140-784$ & $0.7-4.0$ \\
\hline Mango & $184-1,026$ & $1.1-6.2$ \\
\hline Sweet potato & $42-86$ & $0.2-0.4$ \\
\hline \multicolumn{3}{|l|}{ Children 4-6 years } \\
\hline Tangerine & $158-882$ & $0.8-4.5$ \\
\hline Mango & $207-1,154$ & $1.2-7.0$ \\
\hline Sweet potato & 47-96 & $0.2-0.4$ \\
\hline \multicolumn{3}{|l|}{ Children 7-9 years } \\
\hline Tangerine & $175-980$ & $0.9-5.0$ \\
\hline Mango & $230-1,282$ & $1.4-7.8$ \\
\hline Sweet potato & $52-107$ & $0.2-0.4$ \\
\hline \multicolumn{3}{|c|}{$\begin{array}{l}\text { Adolescents } 10-18 \text { years; adult males } 19-65+ \\
\text { years; adult females } 65+\text { years }\end{array}$} \\
\hline Tangerine & $210-1,176$ & $1.1-6.0$ \\
\hline Mango & $276-1,538$ & $1.7-9.3$ \\
\hline Sweet potato & $62-130$ & $0.2-0.5$ \\
\hline \multicolumn{3}{|c|}{$\begin{array}{l}\text { Adult females } 19-65 \text { years (not pregnant or } \\
\text { lactating) }\end{array}$} \\
\hline Tangerine & $175-980$ & $0.9-5.0$ \\
\hline Mango & $230-1,282$ & $1.4-7.8$ \\
\hline Sweet potato & $52-107$ & $0.2-0.4$ \\
\hline \multicolumn{3}{|l|}{ Pregnant females } \\
\hline Tangerine & $281-1,567$ & $1.4-8.0$ \\
\hline Mango & $369-2,052$ & $2.2-12.4$ \\
\hline Sweet potato & $83-173$ & $0.3-0.7$ \\
\hline \multicolumn{3}{|l|}{ Lactating females } \\
\hline Tangerine & $298-1,666$ & $1.5-8.5$ \\
\hline Mango & $392-2,179$ & $2.4-13.2$ \\
\hline Sweet potato & 88-186 & $0.3-0.7$ \\
\hline
\end{tabular}

to eat as much as 8 cups of tangerines and 13 cups of mangos every day under the worst-case scenario. However, mangos have been used to increase vitamin A status (de Pee et al. 1998), and the best-case scenarios for lactating women show more realistic consumptions of about 2 cups per day. In contrast, people of all ages could meet the RNI by eating less than one cup of orange-fleshed sweet potato, which is

Tangerines can provide a substantial amount of vitamin $\mathrm{A}$ in the diet, and could theoretically supply enough vitamin A to be useful as interventions, but sustaining such high intakes of tangerines would be difficult.

\section{Scale of production needed}

We calculated the amounts of tangerines that would be needed to supply the quite realistic. 
RNI for vitamin A to 190 million preschool children and 19.1 million pregnant women most in danger of vitamin A deficiency (WHO 2009). We assumed that $75 \%$ of the preschool children were 1 to 3 years old, and the rest 4 or 5 years old. We also assumed that the tangerines contained high carotenoid concentrations (285 RAEs per 100 grams of edible fruit). In this bestcase scenario, it would take 13,345,538 tons of tangerines to supply vitamin A to all the women and children most at risk for 1 year. We compared this number to the amounts of tangerines and oranges grown per year.

For both tangerines and oranges (table 4), we assessed the production, yield and land area harvested in the world, Asia, Africa, the 77 low-income countries with food deficits, the United States and California. Although the most current information is for 2007 (FAO 2009), today's production is believed to be similar.
It is evident that if all tangerines were bred for high carotenoid concentrations and a percentage of the production were used to provide vitamin A to those most at risk for vitamin A deficiency, then current worldwide production would be sufficient. Indeed, production would be sufficient in the low-income food deficit countries if the two groups of people most at risk ate $70 \%$ of the tangerines. Furthermore, current production levels could be increased. Several changes could make the production of sufficient tangerines more certain; for example, Satsuma mandarin varieties could be selected and bred for higher carotenoid concentrations. Also, if yields in low-income food deficit countries could be increased to those currently attained in California, then, without any changes in land use, their tangerine production would rise to an estimated 32,915,681 tons, or about 2.5 times more than needed to prevent vitamin A deficiency for those most at risk. In Africa,

\begin{tabular}{lccc}
\multicolumn{3}{c}{ TABLE 4. Production quantity, yield and area harvested for tangerines and oranges } \\
\hline & Production & Yield & Area harvested \\
\cline { 2 - 4 } & tons & tons/acre & acres \\
\hline Tangerines & & & \\
World & $30,715,177$ & 6.05 & $5,070,442$ \\
Asia & $22,343,630$ & 5.70 & $3,920,274$ \\
Africa & $1,622,352$ & 7.10 & 228,562 \\
Low-income food deficit countries* & $18,821,515$ & 5.24 & $3,593,415$ \\
United States & 361,554 & 8.12 & 44,500 \\
California & 82,466 & 9.16 & 9,000 \\
Oranges & & & \\
World & $71,388,969$ & 7.32 & $9,754,824$ \\
Asia & $19,626,668$ & 5.53 & $3,549,937$ \\
Africa & $6,356,288$ & 6.82 & 932,283 \\
Low-income food deficit countries & $18,075,046$ & 5.00 & $3,610,084$ \\
United States & $8,109,621$ & 12.15 & 667,200 \\
California & $2,415,983$ & 13.42 & 180,000 \\
\hline
\end{tabular}

Source: California data, USDA Agriculture Statistics Board 2008; all other regions, FAO 2009 (2007 data converted to tons and acres). * These 77 countries meet criteria set by the World Bank and FAO as currently unable to grow enough food to feed their populations.

TABLE 5. Availability for consumption of oranges, tangerines and sweet potatoes, 2003*

\begin{tabular}{lcccc}
\hline & \multicolumn{2}{c}{ Oranges/tangerines } & \multicolumn{2}{c}{ Sweet potatoes (all colors) } \\
\cline { 2 - 5 } & g/person/day & cup/person/day & g/person/day & cup/person/day \\
World & 30.14 & 0.15 & 27.40 & 0.11 \\
Asia & 19.18 & 0.10 & 38.36 & 0.15 \\
Africa & 13.70 & 0.07 & 30.14 & 0.12 \\
Low-income food deficit & 13.70 & 0.07 & 41.10 & 0.16 \\
countries & & & & 0.02 \\
United States & 104.11 & 0.52 & & \\
\hline Source: FAO 2009. & & &
\end{tabular}

such efforts are being made; through ongoing outreach and education, citrus production is increasing and improving (US AID 2007). Finally, because the land devoted to orange production worldwide currently exceeds that of tangerines, some of the land, investment and knowledge used to grow oranges could be used for growing tangerines.

Current production of tangerines in tons is comparable to that of mangos (world production 36,867,502 tons, yield 3.23 tons per acre and 11,390,417 acres harvested). Tangerine production is dwarfed by sweet potato production (world production 118,682,401 tons, yield 5.93 tons per acre and 20,023,450 acres harvested), but most sweet potatoes eaten by humans in low-income food deficit countries are white ones with low concentrations of vitamin A. Orange sweet potatoes, which were introduced later into these countries, are more likely to be used as fuel or fed to livestock (USDA ERS 2009).

\section{Problems of availability}

Of course, the amount of a food that is produced can be much higher than the amount that is available for consumption, especially by the poor. For example, a crop might be exported to other countries, used for biofuel or animal feed, or spoiled. The amount available for consumption is also an important indicator of its acceptability and how well it might serve as a food-based intervention to prevent vitamin A deficiency. Food availability data is less recent than food production data and is subject to more uncertainty. No data has been gathered for mangos, and the white- and orangefleshed types of sweet potatoes are not separated in the data, nor are tangerines and oranges. No data exists on the availability of oranges and tangerines for consumption in California, though it is likely to be at least as high as that of the United States overall since citrus is a major crop in California and good quality fruit is relatively inexpensive and abundant.

Even though the data is limited, it shows that oranges, tangerines and sweet potatoes are not available in sufficient amounts to prevent vitamin A deficiency in people most at risk (table 5). This is because most people at risk for vitamin A deficiency are poor and live in remote areas with bad roads and intermittent 
electricity. Production at the village level is often inefficient and storage conditions inadequate, so spoilage and waste is high, increasing costs and decreasing availability. Major producers typically export tangerines to other countries, which is simpler and more profitable. Several major producers of tangerines, including China, Brazil, Iran, Thailand, Egypt and Pakistan, also have moderate levels of vitamin A deficiency (fig. 1).

\section{Tangerines' potential to help}

We used nutritional, agricultural and population data to evaluate the potential of oranges and tangerines to prevent vitamin A deficiency. Satsuma mandarin tangerines are good sources of vitamin A, providing up to 285 RAEs per 100 grams of fruit. In our best-case estimate, young children could obtain $100 \%$ of their recommended nutrient intake of vitamin A by eating 0.7 cup of tangerines per day, while pregnant or lactating women could meet their RNI by eating 1.5 cups of tangerines per day.

These amounts are reasonable, though perhaps not sustainable on a long-term basis. Tangerines could supply substantial amounts of vitamin A to individuals, which cannot be said for oranges,

\section{References}

Black RE, Allen RH, Bhutta ZA, et al. 2008. Maternal and child undernutrition: Global and regional exposures and health consequences. Lancet 371:243-60.

Burri BJ, Chang JST, Neidlinger T. 2011. Betacryptoxanthin and alpha-carotene-rich foods have greater apparent bioavailability than beta-carotene-rich foods in Western diets. Br J Nutr 105:212-9.

Burri BJ, Turner T. 2009. Evaluating the effectiveness of beta-carotene-rich food interventions for improving vitamin A status. In: Haugen L, Bjornson T (eds.). Beta Caro tene: Dietary Sources, Cancer and Cognition. Haupergne, NY: Nova Sci Pub. p 120-39.

Davis C, Jing H, Howe JA, et al. 2008. Beta-cryptoxanthin from supplements or carotenoid-enhanced maize maintains liver vitamin A in Mongolian gerbils (Meriones unguiculatus) better than or equal to beta-carotene supplements. Br J Nutr 100:786-93.

de Pee S, West CE, Permaesih D, et al. 1998. Orange fruit is more effective than are dark-green, leafy vegetables in increasing serum concentrations of retinol and betacarotene in schoolchildren in Indonesia. Amer J Clin Nut 68:1058-67.

[FAO] Food and Agriculture Organization of the United Nations. 2004. Vitamin and Mineral Requirements in Human Nutrition, 2nd ed. World Health Organization. Geneva, Switz. http://whqlibdoc.who.int/publications/2004/9241546123.pdf (accessed April 15, 2010).

FAO. 2009. FAOSTAT Crops and Livestock Products, 2007. http://faostat.fao.org/site/535/default.aspx\#ancor (accessed Oct. 22, 2009) which contain far less vitamin A-forming carotenoids.

In our best-case estimate, current global tangerine production meets the RNI for all of the young children and postpartum women most at risk for vitamin A deficiency. Furthermore, production might increase substantially if farmers in developing countries were able to adapt for their own use the highcarotenoid varieties of tangerines bred by California food scientists and the highyield farming procedures of California farmers. Currently, there are no major environmental issues associated with growing tangerines, and essentially all of the tangerines produced are eaten by people, not used for animal feed or fuel. Finally, tangerines are relatively durable, easy to prepare and store, and available during fall and winter when the mangos, peppers and green leafy vegetables that supply much of the vitamin A in countries with food deficits are scarce. In theory, tangerines have the potential to help prevent vitamin A deficiency worldwide.

Unfortunately, the current availability of tangerines and oranges for consumption is too low to prevent global vitamin A deficiency. Availability is also the major obstacle for other foods, such as orange-fleshed sweet potatoes, that have the potential to prevent vitamin A deficiency. Looking to the future, breeding strategies to increase concentrations of vitamin A-forming carotenoids in tangerines will be useful. However, it may be even more important to increase the availability and acceptability of tangerines and other foods rich in vitamin A-forming carotenoids for people at risk. The availability and acceptability of these crops may make the difference between the success and failure of food-based interventions to prevent vitamin A deficiency.

\section{B.J. Burri is Research Chemist, J.S.T. Chang was} Graduate Student Researcher, and T. Turner is Graduate Student Researcher, USDA Agricultural Research Service, Western Human Nutrition Research Center (WHNRC), located at UC Davis.

Barbara Sutherland, Associate Staff Scientist, Children's Hospital Oakland Research Center (CHORI) (former Director, Expanded Food and Nutrition Education Program, UC Davis Department of Nutrition), served as Guest Associate Editor for this article. This work was supported in part by the U.S. Department of Agriculture's Agricultural Research Service.
Haskell MJ, Jamil KM, Hassan F, et al. 2004. Daily consumption of Indian spinach (Basella alba) or sweet potatoes has a positive effect on total-body vitamin A stores in Bangladeshi men. Amer J Clin Nutr 80:705-14.

Haskell MJ, Pandey P, Graham JM, et al. 2005. Recovery from impaired dark adaptation in nightblind pregnant Nepali women who receive small daily doses of vitamin $A$ as amaranth leaves, carrots, goat liver, vitamin A-fortified rice or retinyl palmitate. Amer J Clin Nutr 81:461-71. [IOM] Institute of Medicine. 2000. Dietary Reference Intakes for Vitamin A, Vitamin K, Arsenic, Boron, Chromium, Copper lodine, Iron, Manganese, Molybdenum, Nickel, Silicon, Vanadium, and Zinc. Food and Nutrition Board. Washington, DC: Nat Acad Pr. 773 p.

Ladaniya MS. 2008. Citrus Fruit: Biology, Technology and Evaluation. Amsterdam: Acad Pr. 576 p.

Mudur G. 2001. Deaths trigger fresh controversy over vitamin A programme in India. Brit Med J 323:1206.

Perkins-Veazie P. 2007. Carotenoids in watermelon and mango. Acta Hort 746:259-64.

Rodriguez-Amaya DB. 2003. Food carotenoids: Analysis, composition and alterations during storage and processing foods. Forum Nutr 56:35-7.

Ruel MT. 2001. Can Food-based Strategies Help Reduce Vitamin A and Iron Deficiencies? A Review of Recent Evidence. International Food Policy Research Institute. Washington, DC. 77 p.

Schlatterer J, Breithaupt DE. 2005. Cryptoxanthin isomers in oranges, orange juice and other fruits. J Agric Food Chem 53:6355-61.

Sommer A, West KP, Olson JA, Ross AC. 1996. Vitamin A Deficiency: Health, Survival and Vision. New York, NY: Oxford Univ Pr. 438 p.
Stein AJ, Sachdev HPS, Qaim M. 2006. Potential impact and cost effectiveness of Golden Rice Nature Biotech 24:1200-1 (and suppl info)

[US AID] US Agency for International Development. 2007. Growing Citrus in Nigeria. Commercial Crop Production Guide. www.ics-nigeria.org

[USDA] US Department of Agriculture. 2008. Citrus Fruits 2008 Summary. Agriculture Statistics Board. www.nass. usda.gov (accessed Oct. 13, 2009).

[USDA ARS] USDA Agricultural Research Service. 1993. Carotenoid Database on Individual Fruits and Vegetables. www.nal.usda.gov/fnic/foodcomp/Data/Carot/file1.dat (accessed Oct. 22, 2009).

USDA ARS. 2009. National Nutrient Database for Standard Reference, Release 22. www.nal.usda.gov/fnic/ foodcomp/search (accessed Oct. 20, 2009).

[USDA ERS] USDA Economic Research Service. 2009. Ag ricultural Baseline Projections: Global Agricultural Trade, 2008-17. www.ers.usda.gov/Breifing/Baseline/trade.htm (accessed Nov. 1, 2009)

Veda S, Kamath A, Platel K, et al. 2006. Determination of bioaccessibility of beta-carotene in vegetables by in vitro methods. Mol Nutr Food Res 50:1047-52.

West KP Jr, Sommer A. 2002. Vitamin A programme in Assam probably caused hysteria. Brit Med J 324:791.

[WHO] World Health Organization. 2009. Global Prevalence of Vitamin A Deficiency in Populations at Risk, 1995-2005. WHO Global Database on Vitamin A Deficiency. Geneva, Switz. http://whqlibdoc.who.int/ publications/2009/9789241598019_eng.pdf.

Yano M, Kato M, Ikoma Y, et al. 2005. Quantitation of carotenoids in raw and processed fruits in Japan. Food Sci Technol Res 11:13-8. 